University of Nebraska - Lincoln

DigitalCommons@University of Nebraska - Lincoln

Faculty Papers and Publications in Animal

Science

Animal Science Department

2010

Development and usage of eXtension's HorseQuest: An online resource

\author{
E. A. Greene \\ University of Vermont, betsy.greene@uvm.edu
}

A. S. Griffin

University of Kentucky

J. Whittle

University of Kentucky

C. A. Williams

Rutgers University

A. B. Howard

University of Vermont

See next page for additional authors

Follow this and additional works at: https://digitalcommons.unl.edu/animalscifacpub

Part of the Animal Sciences Commons

Greene, E. A.; Griffin, A. S.; Whittle, J.; Williams, C. A.; Howard, A. B.; and Anderson, Kathleen P., "Development and usage of eXtension's HorseQuest: An online resource" (2010). Faculty Papers and Publications in Animal Science. 697.

https://digitalcommons.unl.edu/animalscifacpub/697

This Article is brought to you for free and open access by the Animal Science Department at DigitalCommons@University of Nebraska - Lincoln. It has been accepted for inclusion in Faculty Papers and Publications in Animal Science by an authorized administrator of DigitalCommons@University of Nebraska - Lincoln. 


\section{Authors}

E. A. Greene, A. S. Griffin, J. Whittle, C. A. Williams, A. B. Howard, and Kathleen P. Anderson 


\title{
Development and usage of eXtension's HorseQuest: An online resource ${ }^{1}$
}

\section{E. A. Greene, ${ }^{* 2}$ A. S. Griffin, $\dagger$ J. Whittle, $\uparrow$ C. A. Williams, $\ddagger$ A. B. Howard, $\S$ and K. P. Anderson\#}

\begin{abstract}
*Department of Animal Science, University of Vermont, Burlington 05405; †eXtension, University of Kentucky, Lexington 40546; $\ddagger$ Department of Animal Science, Rutgers, the State University of New Jersey,

New Brunswick 08901; §Statistical Consulting \& Software Support, University of Vermont, Burlington 05405-1739; and \#Department of Animal Science, University of Nebraska, Lincoln 68583-0908
\end{abstract}

\begin{abstract}
Xtension (pronounced e-extension) is an online resource transforming how faculty can collaborate and deliver equine education. As the first Community of Practice launched from eXtension, HorseQuest (HQ) offers free, interactive, peer-reviewed, online resources on a variety of equine-related topics at http:// www.extension.org. This group has adapted traditional educational content to the online environment to maximize search engine optimization, to be more discoverable and relevant in the online world. This means that HQ resources are consistently being found on the first page of search results. Also, by researching key words searched by Internet users, HQ has guided new content direction and determined potential webcast topics based on relevance and frequency of those searches. In addition to establishing good search engine optimization, HQ has been utilizing the viral networking aspect of YouTube by uploading clips of existing equine educational videos to YouTube. HorseQuest content appears
\end{abstract}

in mainstream media, is passed on by the user, and helps HQ effectively reach their community of interest (horse enthusiasts). HorseQuest partners with My Horse University to produce webcasts that combine concise knowledge exchange via a scripted presentation with viewer chat and incoming questions. HorseQuest has produced and published content including 12 learning modules, 8 webchats, 21 webcasts, and 572 videos segments. After the official public launch, there was a steady increase in average number of visits/mo and average page views/mo over the 26 -mo period. These regressions show a statistically significant increase in visits $(P<0.001)$ of approximately 450 visits per month and a significant increase in page views $(P=0.004)$ of about 373 page views per month. HorseQuest is a resource for several state $4-\mathrm{H}$ advancement and competition programs and will continue to be incorporated into traditional extension programs, while reaching and affecting global audiences.

Key words: extension, horse, HorseQuest, Internet, social networking

(0) 2010 American Society of Animal Science. All rights reserved.

J. Anim. Sci. 2010. 88:2829-2837 doi:10.2527/jas.2010-2810

\section{INTRODUCTION}

Web-based extension programming has become more widespread and accepted (Kallioranta et al., 2006; Sobrero and Craycraft, 2008; Sellers et al., 2009) in the last decade. Forest product extension specialists in Oregon and Louisiana use Web-based communities to facilitate outreach and extension efforts to the forestry industry within their states (Kallioranta et al., 2006). Additionally, family care-giving extension programming has been strengthened and enhanced through educa-

\footnotetext{
${ }^{1}$ Funding provided by eXtension (Lincoln, NE) and Purina (Gray Summit, MO).

${ }^{2}$ Corresponding author: betsy.greene@uvm.edu

Received January 8, 2010.

Accepted March 30, 2010.
}

tional resources provided in a similar national one-stop Web site (Sellers et al., 2009). Peterson et al. (1999) reported on a public Internet site where families can do a self-scoring assessment in areas such as family life, financial management, and nutrition and food safety. Although access to immense amounts information on the Internet is becoming easier, the actual measurement of learning and positive changes in behavior can be difficult to document because of the open access to most Web-based material. Further, the ability of the user to distinguish between good quality, fact-based online content and opinion or propaganda can vary immensely (Anderson and Rainie, 2010).

In 2004, extension directors and administrators from the 1862 and 1890 land grant universities voted to direct a portion of their operating budgets to develop eXtension (pronounced e-extension). eXtension is an 
educational partnership of more than 70 universities that was created to extend the land grant mission to provide objective, science-based information to the public, answer clientele questions anywhere and anytime, and guide user decisions. This medium has engaged academic equine experts and Internet users together in an online community through providing customized answers to questions and interactive up-to-date, peerreviewed content.

HorseQuest (HQ) originated as a group of Southern Regional Extension Horse Specialists and quickly expanded by recruitment of national equine specialists and county extension professionals from land grant universities. In 2005, the HQ Community of Practice (CoP) was awarded grant funds and was the first pioneer $\mathrm{CoP}$ to publicly launch in November 2006. As of July, 2009, the HQ team had over 50 contributing equine experts from 32 institutions in 29 states that work together to bring trusted science-based and professionally reviewed information to clientele in a timely manner.

The HQ users consist of the general public, county extension agents/educators, young people, college students, veterinarians, university professors, farriers, farm workers, and other equine professionals. The American Horse Council reports that 4.6 million Americans are directly involved with horses as owners, service providers, employees, or volunteers, and the horse community encompasses all facets of the US population and income categories (AHC, 2005).

The objectives of this project were 1) to engage the expertise of equine specialists at a national level; 2) to provide a one-stop, trusted, equine resource for a national audience; and 3) to track the usage and impact of HQ through user metrics and evaluation over time.

\section{MATERIALS AND METHODS}

All data collected during this project has been determined to be exempt under the University of Vermont Institutional Review Board. The HQ CoP began creating content in 2005 and has continued developing, peer-reviewing, publishing, and identifying new content to maintain an engaging repository of equine resources at http://www.extension.org/horses. Content in eXtension is managed by 2 open-source content management systems, MediaWiki (http://www.mediawiki.org) and Ruby on Rails (http://rubyonrails.org). Components of HQ include learning modules, webcasts, instructional videos, frequently asked questions, and general articles of information.

\section{Learning Modules}

The HQ team defined priority areas for the development of lessons based on user feedback, the search results of consumers using published content, and the frequency and type of incoming equine questions to eXtension from the public. Learning modules were constructed to be self-paced and range in level of difficulty based upon topic and intended audience. For example, an introductory curriculum has been developed to field basic horse ownership and care needs, whereas more specific certificate programs have been piloted to serve the "train the trainer" youth horse leadership requests by $4-\mathrm{H}$ and other youth horse organizations. Learning modules have been created and viewed using eXtension's Moodle courseware (http://campus.extension. org) and contain a combination of curriculum text, complementary images, and video clips to support the learning experience. Between May 2008 and April 2009, a survey was developed and administered using Instant Survey (http://www.instantsurvey.com) to determine overall satisfaction of the users and outcome data regarding how the learning modules have influenced practices, perspectives, or both, of the participants.

\section{Webchats/Webcasts with Experts}

Direct online interactive instruction and discussion with clients was initially conducted by HQ through quarterly webchats. Webchats consisted of an optional prechat reading lesson focused on a specific topic combined with $1 \mathrm{~h}$ of synchronous online text chat between university equine specialists and users through the Volcano chat application.

In 2007, HQ partnered with My Horse University (MHU) at MSU Global of Michigan State University to provide more focused online direct teaching through interactive webcasts. These webcasts combine concise knowledge exchange via a scripted presentation and allow interactive text chat by the viewer. This interactivity is encouraged throughout the live webcast where participants log in at the time of the live webcast and listen to the speaker, view the presentation slides, and interact with the presenter or other expert. At the end of the presentation, the speaker addresses any additional questions. Clientele must preregister for the live webcast but can access the archived webcast at their convenience from the MHU Web site (http://www.myhorseuniversity.com/resources/webcasts/archived).

A survey was developed using Instant Survey (http:// www.instantsurvey.com) to determine overall satisfaction of the participants and outcome data regarding how the webcasts have influenced practices, perspectives, or both, of the participants. Between January 2009 and September 2009, the survey was emailed to webcast registrants with a reminder that the recorded webcast could be viewed on the MSU Web site.

\section{Instructional Video and YouTube}

In an attempt to broaden the audience of HQ, an eXtension horse channel (eXHorses) was created for free on YouTube (http://www.youtube.com/user/eXHorses). This channel can potentially deliver existing instructional horse videos in an online access environment to an estimated 100 million visitors per month. These peer-reviewed, instructional videos originated 
from materials created by university equine professionals at their home institutions.

Beginning in June of 2008, HQ began uploading short video clips (8 to $10 \mathrm{~min}$ ). Due to YouTube video length restrictions, these videos were brought together into 8 play lists that organize these clips into their respective originating video. YouTube user data are available for channel evaluation that allows HQ to determine the demographics of this new public community, extract user feedback through video commenting, and rank video usefulness by the users on a star rated scale of excellent (5 stars), great (4 stars), good (3 stars), average (2 stars), or poor (1 star).

\section{Frequently Asked Questions and Ask an Expert}

Internet users search for answers to questions in equine subject areas such as health, management, marketing, nutrition, reproduction, selection, and training and behavior in the existing frequently asked questions (FAQ) database. All published FAQ have been peerreviewed, copyedited, and published by HQ experts. Users can also receive customized answers to their new questions by using the ask-an-expert (AaE) feature. Users must first conduct a search of all existing FAQ using key words to reduce the incidence of redundant question submittal. If there is not a representative FAQ, then they submit their question. New questions are routed to a horse expert in the subject area for initial response, and then the answer is captured in the FAQ application for further peer review, adaptation, and publishing. The eXtension FAQ/AaE application uses Ruby on Rails technology to manage incoming and existing FAQ.

\section{Articles of Information}

The HQ team initially agreed on a standard set of subject areas for creation of the best-of-the-best articles that addressed the following categories: breed, diseases, ethics, exercise and performance, facilities, feeding management, feeds, health, hoof care, management, nutrition, reproduction and breeding, selection and use, and training and behavior. An inventory of existing content was developed by extension specialists and used as seed materials for these category areas. As needed, unique articles were written for peer reviewing, copyediting, and publishing in eXtension. The CoP members peer-review articles related to their specific areas of expertise. After the articles have been reviewed by $2 \mathrm{CoP}$ members, they are sent to an eXtension copy editor and back to a content expert for final review before publishing. Primary authors of content are identified on the published form of the article, whereas reviewers are identified in the article metadata. This provided the initial basic content that populated the $\mathrm{HQ}$ site in its initial development and serves as the methodology for new materials.
To be more proactive and address emerging issues, HQ has published articles that are considered hot topics such as materials surrounding horse slaughter, the unwanted horse, and the financial crisis as it relates to an equine enterprise or hobby. To further keep articles relevant and timely, $\mathrm{HQ}$ of eXtension publishes equine-related news as found in the news feeds of the land grant system. Calendar events are added by $\mathrm{CoP}$ members to promote activities at local, state, and national levels pertaining to horses. All article content is published using eXtension's Media Wiki content management system, and events are published using the calendar operated by Ruby on Rails.

\section{Funding and Partnerships}

HorseQuest has primarily been funded by competitive grants through eXtension for content development, management, and leadership funds. Additionally, some commercial sponsorships were acquired and partnerships were developed, which support funding and content development.

\section{Statistics}

HorseQuest site usage statistics (visits and page views) collected by Google Analytics (http://www. google.com/analytics/index.html) over a 26-mo period were analyzed using simple linear regression (SPSS, Chicago, IL). Average page views by day of week were compared with ANOVA, and weekend vs. weekday page views were contrasted. An ANOVA was done to compare page views across months and days of week.

\section{RESULTS AND DISCUSSION}

\section{General Web Site Usage}

Horse content developed by the HQ CoP can be found at eXtension (http://www.extension.org/horses). Content development began in 2005, and through April 2009 , the group has produced and published content including 12 learning modules, 8 webchats, 21 webcasts, and 572 video segments. In addition, 1,191 frequently asked questions have been reviewed and published, 1,606 incoming ask-an-expert questions were resolved, and 1,572 published and in-progress articles with an additional 239 calendar events and 297 news articles were created as of March 2009. Initial seed content was first made available to the public in September of 2006 with the National eXtension official public launch occurring in February 2008. From the official public launch (February 2008), Google Analytics data indicate customers access eXtension content via several methods with $78 \%$ entering the site by searching (e.g., Google, Yahoo) for answers to their questions, $13 \%$ coming from referring sites that link to eXtension content, and $9 \%$ of users come directly to the site by typing the Internet address or accessing their bookmarks. 


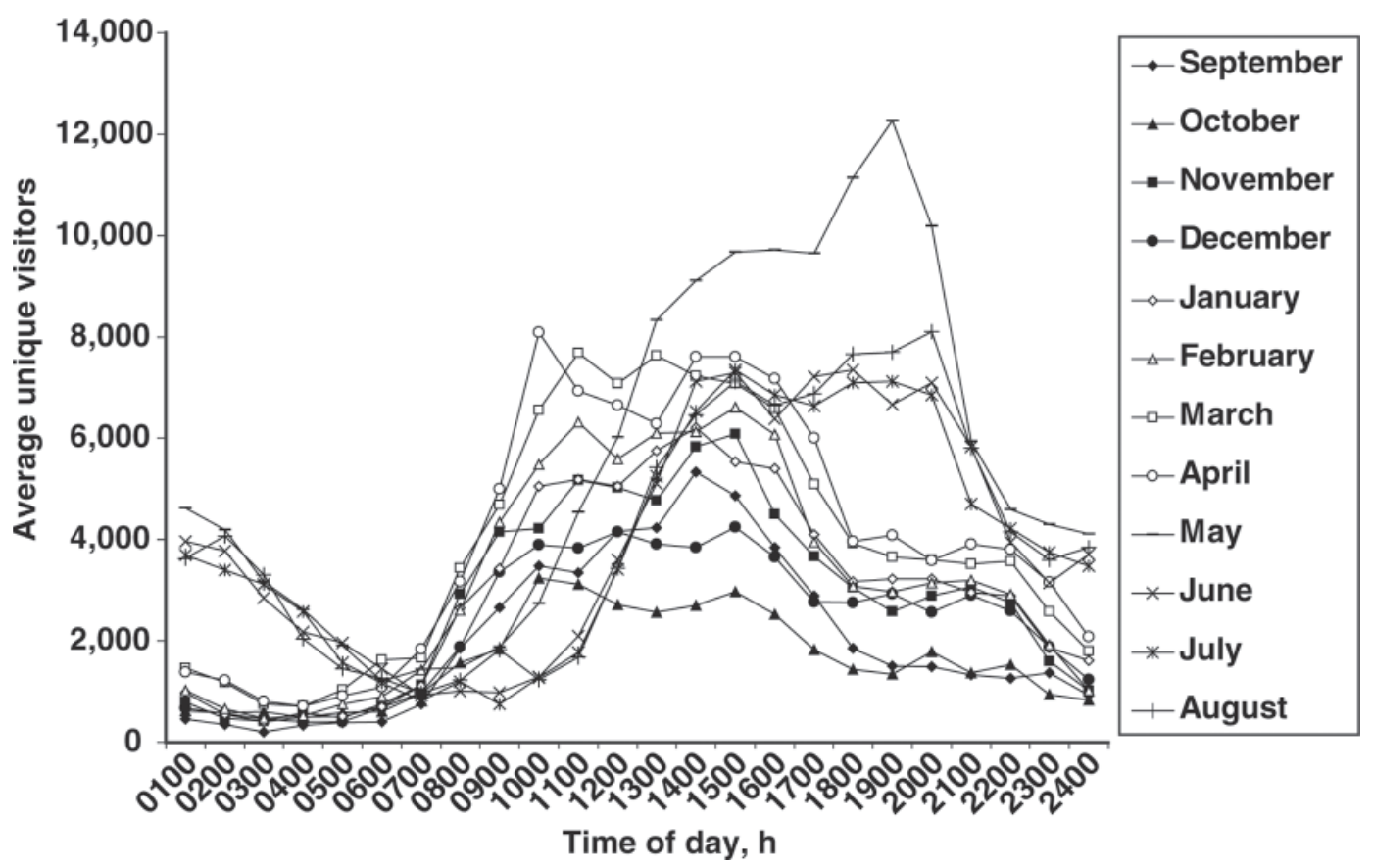

Figure 1. Prepublic launch average unique visitors to HorseQuest by hour of the day for each month (September 2006 to August 2007).

Search engine optimization has been improved through methods such as the utilization of highly searchable key words and phrases that were identified by applications and strategic contextual links. Furthermore, page titles and content summaries have been developed containing common key words used by the public searching the Internet for equine information. Improved online discoverability of HQ has increased traffic and volume to the site.

In a 1-yr period before the official public launch of HQ (from September 2006 to August 2007), site traffic statistics were collected by hour of day as well as by day of week. Figure 1 shows the distribution of average unique visitors by hour of day for each month. Figure 2 shows the distribution of total page hits by hour of day for each month. Both figures show a slightly different trend for the 4-mo period from May to August 2007 than for the previous 8 mo, especially in the late night to early morning hours. May 2007 was the greatest, potentially due to an official public launch of the horse site at a major regional multi-day equine educational event/consumer trade show attended by over 8,500 equine enthusiasts. Associated with the event was a series of 3 episodes of a regional agricultural television show that publicized the event and eXtension. The next 3 mo showed a delayed decline in usage $(2,100$ vs. $1,600)$.

After the official public launch, Google Analytics data show a steady increase in average number of visits per month (Figure 3) and average page views per month (Figure 4) over the 26-mo period from March 2007 to April 2009. These regressions show a statistically significant increase in visits $(P<0.001)$ of approximately 450 visits per month and a significant increase in page views $(P=0.004)$ of about 373 page views per month.
These results demonstrate that the multiple methods used to increase clientele traffic to the HQ site (e.g., search engine optimization, YouTube channel creation, webcasts) have been effective.

There was a significant difference in average page views per day based on month from March 2007 to April 2009 (Figure 5; $P<0.001$ ) and a significant difference in average page views per day of week (Figure 6; $P<0.001$ ). The peak page activity took place in March 2008 followed by February and March 2009. Overall, the summer months seemed to have less activity; however, this was not consistent throughout the 25-mo period. Typically, across much of the United States, horse activities are seasonal and weather-dependent. Thus, the 3-mo peak could have reflected a climate change or lull in outdoor horse activities. Preliminary evaluation of data from the 2009 summer months shows a similar decrease in page views during this time of year. Contrasting page views between weekdays and weekends also showed statistically significant differences $(P$ $<0.001$ ), and the same results occurred when including Friday with weekends $(P<0.001)$. The greatest number of page views occurred at the beginning of the week (Monday and Tuesday), followed by a significant decrease $(P<0.05)$ through the rest of the week and weekend. This could be attributed to increased horse activities on the weekend that stimulate questions and drive clientele to seek answers the following week.

\section{Learning Modules}

From 2005 to April 2009, HQ completed 12 learning modules that allow users the opportunity for in-depth information on various topics such as basic horse care, nutrition, pasture management, and equipment. An on- 


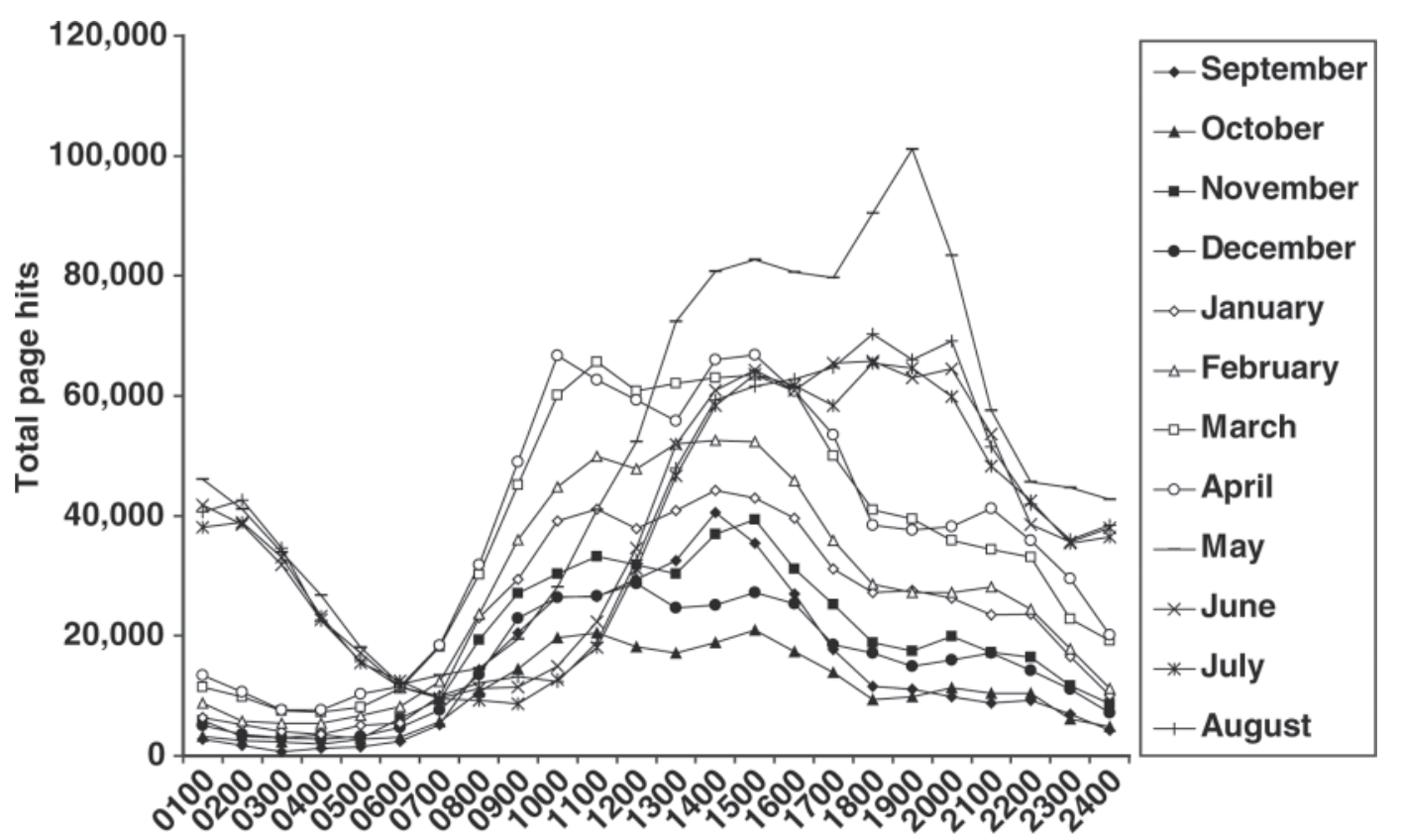

Time of day, $\mathbf{h}$

Figure 2. Prepublic launch total page hits to HorseQuest by hour of the day for each month (September 2006 to August 2007 ).

line survey was constructed and deployed using Instant Survey from May 2008 to April 2009 to evaluate the effects of module content on the user. These optional surveys have documented a cross-section of users who describe themselves as follows: adults (72\%), educators and youth (10\%), parents or guardians and club leaders $(7 \%)$, and industry professionals (3\%). Self-assessment of knowledge gained increased from $79 \%$ ranking 4 or less (with 6 being very knowledgeable, and 1 being little or no knowledge; Trochim, 2006) before viewing a lesson to $96 \%$ ranking 4 or above after viewing the lesson (Table 1). Seventy-nine percent of respondents indicated a willingness to recommend this resource to others. Therefore, this was determined to be an effective way to deliver topic-specific content to self-learners. This avenue also provides extension professionals a

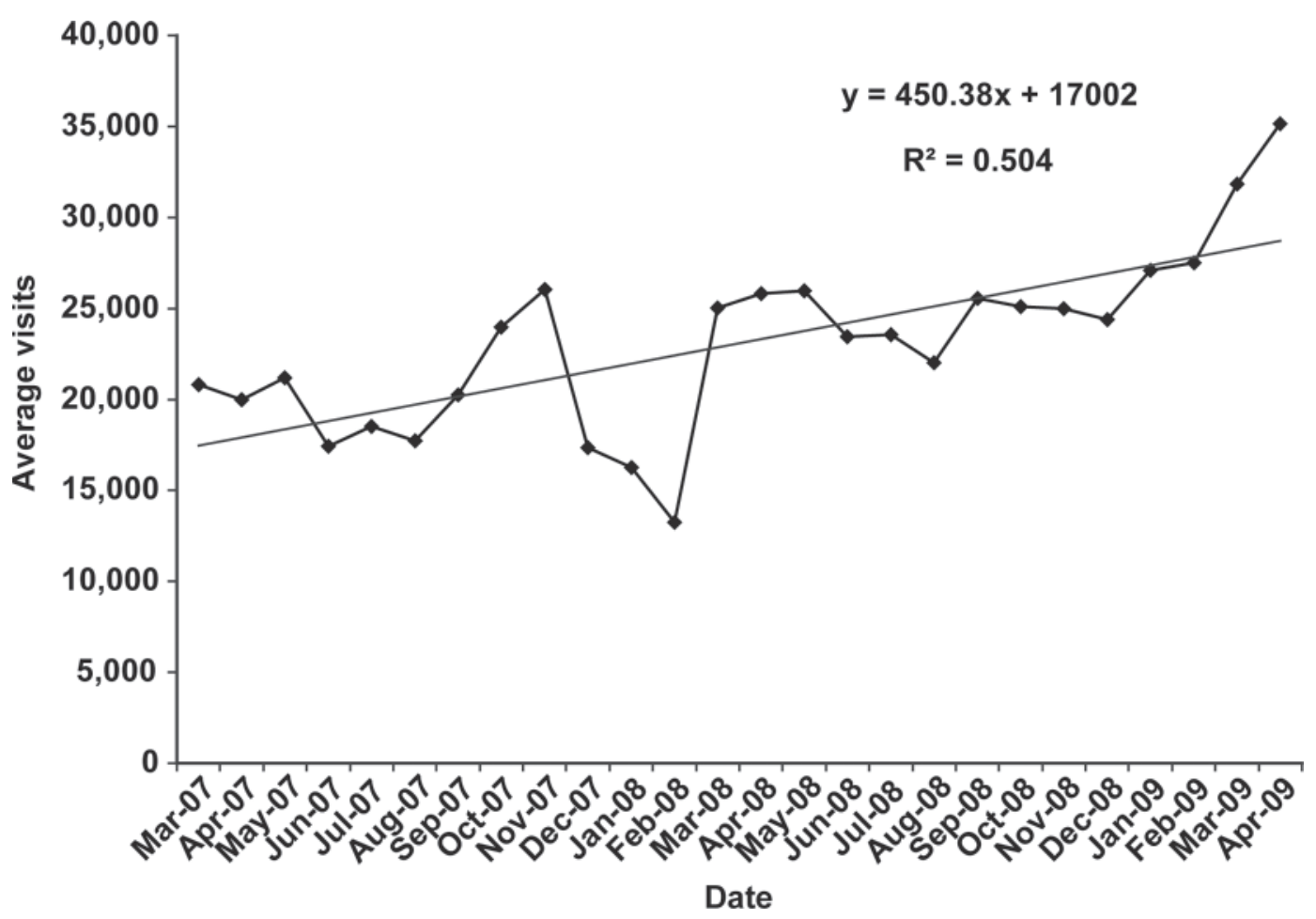

Figure 3. Postpublic launch average number of visits to HorseQuest per month (March 2007 to April 2009). 


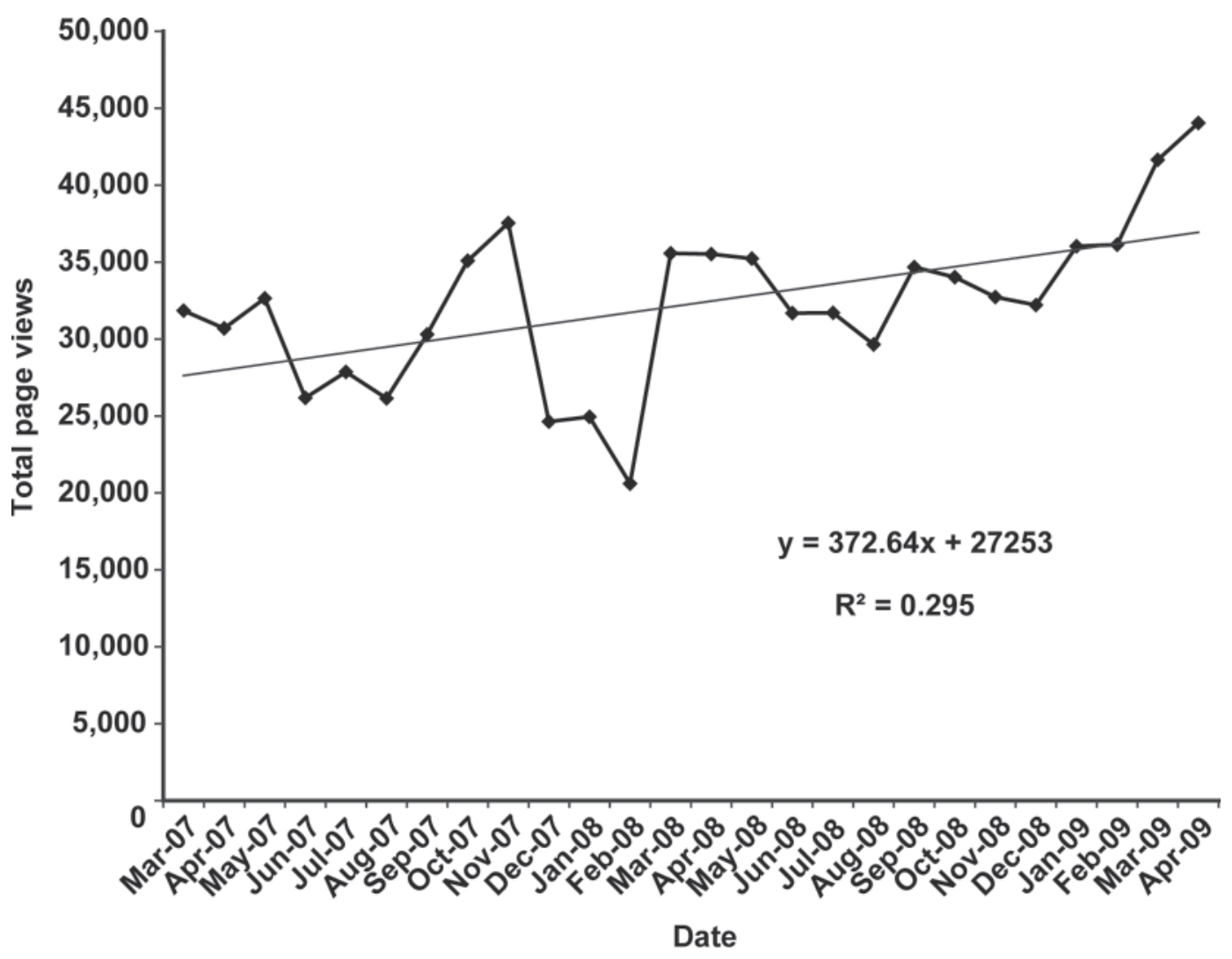

Figure 4. Postpublic launch total number of page views of HorseQuest per month (March 2007 to April 2009).

quick database for continuing education opportunities. The authors used FAQ to help prioritize the learning lesson content development, and the experts used the learning lessons to quickly direct clientele to the appropriate educational material. Locally, multiple specialists have used the Web resource in classrooms and pro-

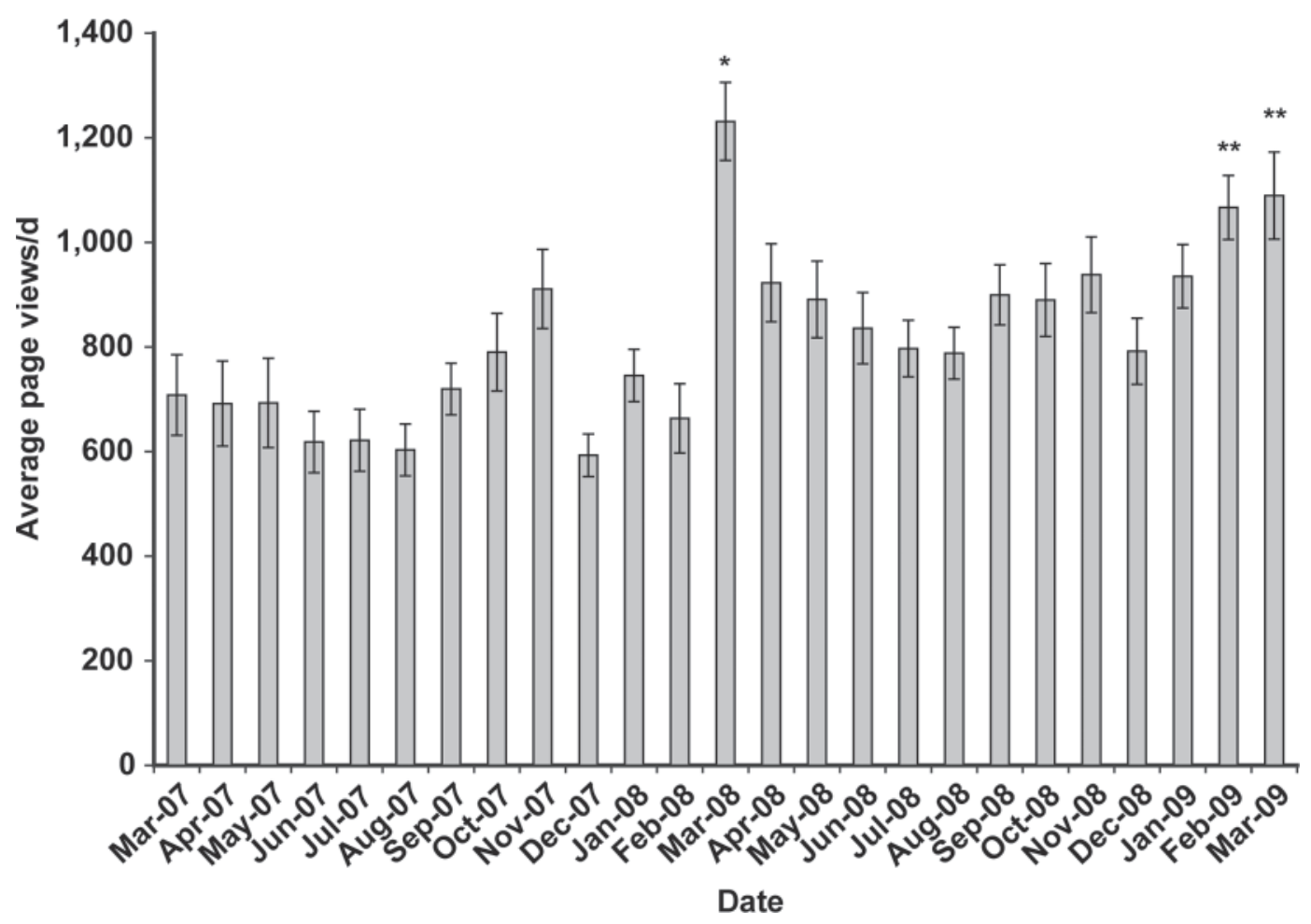

Figure 5. Average number of daily page views of HorseQuest by month (2007 to 2009). *Denotes significant difference from all other months at $P<0.05$. **Denotes no significant difference between month at $P<0.05$. 
Table 1. User knowledge before and after viewing learning modules from May 2008 to April 2009

\begin{tabular}{lcc}
\hline \hline $\begin{array}{l}\text { Knowledge } \\
\text { rank }{ }^{1,2}\end{array}$ & $\begin{array}{c}\text { Before viewing, } \\
\%(\mathrm{n})\end{array}$ & $\begin{array}{c}\text { After viewing, } \\
\%(\mathrm{n})\end{array}$ \\
\hline Rank 1 & $14(4)$ & $0(0)$ \\
Rank 2 & $10(3)$ & $0(0)$ \\
Rank 3 & $31(9)$ & $3(1)$ \\
Rank 4 & $24(7)$ & $17(5)$ \\
Rank 5 & $10(3)$ & $41(12)$ \\
Rank 6 & $10(3)$ & $38(11)$ \\
\hline
\end{tabular}

${ }^{1}$ Likert-type scale: $1=$ little or no knowledge to $6=$ very knowledgeable.

${ }^{2}$ Each respondent could only choose 1 option.

gramming throughout their states. Examples include using archived webcasts to bring national talks to local audiences, video clips to show digesta moving through the gastrointestinal tract of the horse, or showing examples of equine artificial gaits, which can be difficult to find. Additionally, animations of the parts of the hoof and the interactive learning lesson for body condition scoring have been used in the field and classroom to supplement presentations.

\section{Instructional Video and YouTube}

Members of the HQ team submitted peer-reviewed instructional videos on topics ranging from horse training and behavior, grooming, horsemanship exercises, safety, showing, grooming, selection and use, and hoof care. Videos placed on the HQ site were subdivided into short segments for easier downloading and viewing.

From June 2008 to April 2009, the eXHorses channel was viewed 6,005 times, whereas the 111 uploaded videos were viewed a total of 125,277 times. The channel has 310 individual subscribers that represent registered YouTube users. Fifty-six percent of the viewers are female, with the greatest percentage of all viewers (39\%) between the ages of 45 to 54 years, followed by 35 to $44(21 \%), 55$ to $64(15 \%), 13$ to $17(11 \%), 25$ to 34 $(7 \%)$, and 18 to $24(5 \%)$. Over this 11 -mo period, $68 \%$ of the HQ videos on YouTube have been rated with the majority $(75 \%)$ receiving the top rating of 5 stars (excellent), whereas 13.6, 9, and $1.1 \%$ were rated a 4 , 3 , and 1 star, respectively. Of the top 10 videos viewed on eXHorses, 9 were related to training, with the top videos related to neck reining, pivoting, and teaching a horse to respond to leg pressure. Since its creation, there were 239 self-referrals to the eXtension HQ site from eXHorses, which represents the choice of a user to visit eXtension HQ from eXHorses.

Using YouTube as a home for extension instructional videos has helped HQ have a presence in an extremely high traffic Internet location. This provides HQ experts with feedback and comments, records outcomes of their efforts, as well as exposing cooperative extension to new populations. The use of social media to deliver and distribute content is a cost-effective method to reach millions of users. Of these users, $57 \%$ have joined a social network and $83 \%$ have watched video clips. YouTube has proven not only to be a good marketing strategy for

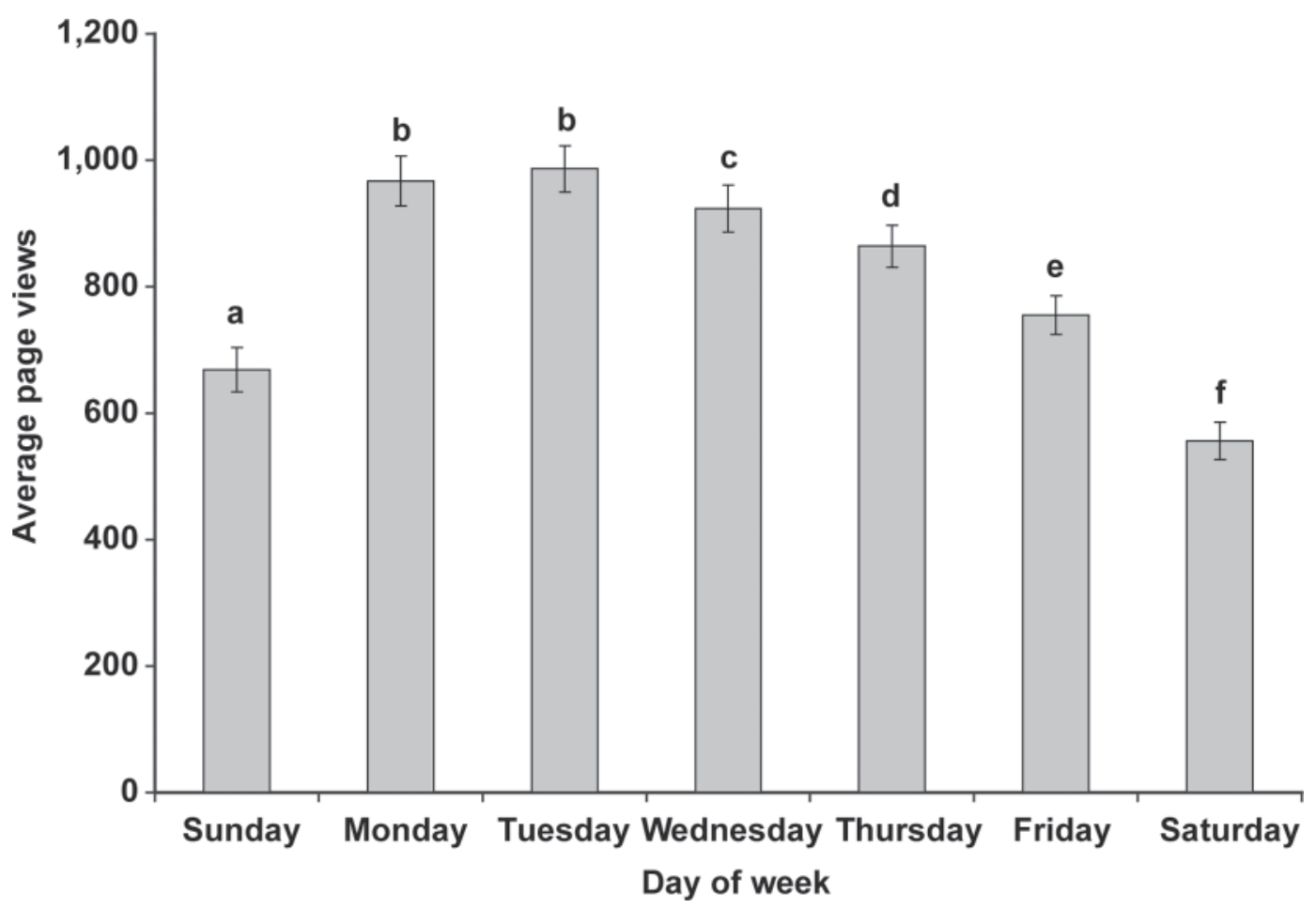

Figure 6. Average number of page views of HorseQuest by day of the week (2007 to 2009). Different letters indicate significant difference at $P<0.05$. 
Table 2. User knowledge before and after webcast viewing from January 2007 to April 2009

\begin{tabular}{lcc}
\hline \hline $\begin{array}{l}\text { Knowledge } \\
\text { rank }^{1,2}\end{array}$ & $\begin{array}{c}\text { Before viewing, } \\
\%(\mathrm{n})\end{array}$ & $\begin{array}{c}\text { After viewing, } \\
\%(\mathrm{n})\end{array}$ \\
\hline Rank 1 & $4(3)$ & $1(1)$ \\
Rank 2 & $18(13)$ & $1(1)$ \\
Rank 3 & $23(17)$ & $5(4)$ \\
Rank 4 & $31(23)$ & $16(12)$ \\
Rank 5 & $15(11)$ & $53(39)$ \\
Rank 6 & $9(7)$ & $22(16)$ \\
\hline
\end{tabular}

${ }^{1}$ Likert-type scale: $1=$ little or no knowledge to $6=$ very knowledgeable.

${ }^{2}$ Each respondent could only choose 1 option.

HQ, but also has emerged as a smart choice for eXtension to host online instructional videos because YouTube also allows for embedding these videos directly into a Web page.

\section{Webchats/Webcasts with Experts}

Topics for the webchats and webcasts were identified by researching key words searched by Internet users, FAQ, current industry issues, and general user feedback. The topics were advertised to the public, and suggested prechat informational fact sheets were made available. Between January 2006 and November 2007, eight webchats were offered by HQ, in which at least 3 topic area experts and one facilitator were available on each chat. These experts responded to questions targeted to the selected topic and encouraged open discussion between the clientele and experts. The 8 webchats that were conducted involved 14 universities from all regions and nearly 150 customers. Approximately 89\% of the participants indicated they found answers to their questions.

eXtension HQ experts in partnership with MHU conducted free, monthly webcasts from September through May of each year to reach out to the equine industry and create a learning community. This partnership uses eXtension national experts and MHU technology and resources to meet the needs of equine clientele. The live webcast topics include areas such as horse farm management, horse health, nutrition, and equine-related environmental issues. All of the webcasts are recorded and made available on the MHU Web site for viewing after the live event.

Between January of 2007 and April 2009, seventeen free webcasts were offered with approximately 600 in total attendance. As of April 2009, 1,400 individuals accessed the archived webcasts. Post-webcast survey results indicated that the webcast was very useful $(58 \%)$ or somewhat useful (41\%) to help viewers make more informed horse management decisions. Additionally, $77 \%$ would recommend the webcasts to other people, and $67 \%$ planned to make at least one change in their horse management practices based on information gained from viewing the webcast. Examples of reported man- agement changes include vaccinating pregnant mares for rhinopneumonitis; tracking vital signs of horses as a practice; changing from feeding round bales to smaller, square bales of hay; wetting down hay to decrease dust; ceasing to use hay nets in horse trailers; and increasing the time that horses are turned out in pastures or paddocks. Self-assessment of participants for the level of knowledge gained increased from $75 \%$ ranking of 4 or less (on a scale of 1 to 6; Trochim, 2006) before viewing the webcast, to $90 \%$ ranking of 4 or greater after viewing the webcast (Table 2).

Locally, multiple specialists have used the Web resource in classrooms and programming throughout their states. Examples include 1) archived webcasts are used to bring national presentations to local audiences (e.g., Dr. Lenz on The Unwanted Horse), 2) 4-H youth groups using webcasts as learning activities at meeting, 3) university faculty showing webcasts in courses, and 4) horse industry professionals (veterinarians, extension educators) referring clients to the webcasts for more information on specific topics.

\section{$F A Q$ and $A a E$}

Horse specialists, faculty, and extension professionals continuously answer incoming questions for the AaE resource. From September 2006 to March 2009, the HQ team has resolved 1,606 new FAQ submitted by clientele from the public Web site. When answering the questions, experts formulate private answers for the individual asking the specific question. However, when converting a question to an FAQ, it is adapted to a broader audience by making generalizations out of the specific details. Frequently asked questions are peerreviewed through a 4 -step process including 2 expert reviews, a copyedit, and a third and final review before publishing. As of March 2009, there were 1,191 publicly searchable FAQ available at eXtension that have been viewed 18,558 times.

\section{Summary}

Usefulness of materials and user willingness to obtain relevant information via an online learning environment has been reported by High and Jacobson (2005) through a Web site developed for natural resource education. They found that $64 \%$ of the private forestry landowners would use the Web site for their work. Furthermore, $62 \%$ would use the site again or tell a friend. Other online extension programming and educational courses collect personal data and can document outcomes by individuals participating in online courses requiring registration. However, measuring specific outcome data for individual users is difficult for $\mathrm{HQ}$ because users are not required to $\log$ in to view articles or information. Much of the information is viewed anonymously, except when users are required to $\log$ in to submit a question via the AaE tool. On the YouTube channel 
of HQ, users have provided anecdotal information via posted comments on HQ YouTube videos documenting that they have learned new skills and are implementing these skills with their horses. Here, for example, are 2 comments from those postings: "Taught my 12 year old Arabian to neck rein in no time" and "Thank you for all of the great teaching that you are doing here...these are very useful in helping me train my horse."

HorseQuest has been on the forefront of eXtension, often leading the way using modern technology to deliver quality, peer-reviewed educational materials to global equine clientele. HorseQuest has identified quantitative and qualitative methodology to evaluate all aspects of this online equine resource. Use of $\mathrm{HQ}$ has been tracked, documented, and statistically evaluated, showing a continuously increased usage as a value-added educational resource since it became available to the public in September 2006.

\section{LITERATURE CITED}

American Horse Council (AHC). 2005. National Economic Impact of the U.S. Horse Industry. http://www.horsecouncil.org/nationaleconomics.php Accessed Jan. 4, 2010.

Anderson, J., and L. Rainie. 2010. Future of the Internet IV: PEW Future of the Internet. http://www.pewinternet.org/Re-
ports/2010/Future-of-the-Internet-IV.aspx Accessed Mar. 18, 2010.

High, J., and M. Jacobson. 2005. Internet-based natural resource extension. J. of Extension (On-line) 43:3 Article 3RIB9. http:// www.joe.org/joe/2005june/rb9.php Accessed Mar 14, 2010.

Kallioranta, S. M., R. P. Vlosky, and S. Leavengood. 2006. Webbased communities as a tool for extension and outreach. J. of Extension (On-line) 44:2 Article 2FEA4. http://www.joe.org/ joe/2006april/a4.php Accessed Mar. 14, 2010.

Peterson, R., C. Kratzer, I. Leech, K. Stadler, T. Roberts, and M. Summer. 1999. A family check-up: A Web-based, self-assessment program in family life, financial management, nutrition, and food safety. J. of Extension (On-line) 37:6. Article 6TOT2. http://www.joe.org/joe/1999december/tt2.php Accessed Mar. 14, 2010.

Sellers, D. M., A. B. Crocker, A. Nichols, S. D. Kirby, and M. Brintnall-Peterson. 2009. Creating the eXtension Family Caregiving Community of Practice. J. of Extension (On-line) 47:5 Article 5FEA1. http://www.joe.org/joe/2009october/a1.php Accessed Mar. 12, 2010.

Sobrero, P. M., and C. G. Craycraft. 2008. Virtual communities of practice: A 21st century method for learning, programming and developing professionally. J. of Extension. (On-line) 46:5. Article 5FEA1. http://www.joe.org/joe/2008october/a1.php Accessed Mar. 11, 2010.

Trochim, W. M. 2006. Likert scaling. In Research Methods Knowledge Base, 2nd ed. http://www.socialresearchmethods.net/kb/ scallik.php Accessed Jan. 5, 2010. 